\title{
Supporting Information: Quantum chemical
}

\author{
study of a radical relay mechanism for the
}

HydG-catalyzed synthesis of a

\section{$\mathrm{Fe}(\mathrm{II})(\mathrm{CO})_{2}(\mathrm{CN})$ cysteine precursor to the $\mathrm{H}$-cluster of [FeFe] hydrogenase}

\author{
Nanhao Chen, Guodong Rao, R. David Britt*, Lee-Ping Wang* \\ Department of Chemistry, University of California Davis, Davis, California 95616 \\ E-mail: rdbritt@ucdavis.edu, leeping@ucdavis.edu
}

\section{Computational methods}

Structural modeling. The initial HydG structure for the simulations was obtained from the published crystal structure, PDB ID 4WCX. ${ }^{1}$ Herein, only Chain A of the protein dimer was employed in the study as it included the dangler iron. When preparing the simulation input structure, five missing residues in the N-terminal region were omitted and seven missing residues (345-351) were manually added in the middle of the chain. Because the SAM cofactor was missing from Chain A, we modeled its structure by substituting the SAM structure from Chain $\mathrm{C}$ for the corresponding methionine residue in chain A by superposition. The crystal structure included a free alanine (ALA) and sulfur atom (H2S) bonded to the auxiliary cluster, which we interpreted to be identical to the cysteine ligand to the dangler Fe from experimental evidence. ${ }^{2}$ In order to add the missing tyrosine substrate, the crystal 
structure of the tryptophan lyase NosL (pdb ID: 4R34) ${ }^{3}$ was used as a template to place the tyrosine substrate into HydG by superposition with the tryptophan substrate in NosL; the interactions between tyrosine and $\mathrm{HydG}$ were then optimized using a docking calculation. ${ }^{4}$ The protonation of all residues was decided based on comparing the experimental $\mathrm{pH}$ value (7.0) with standard side chain pKa values, and His265 was protonated as HID (N $\delta$ is protonated) as $\mathrm{N} \epsilon$ is coordinated to the dangler iron. Given the tyrosine substrate, two protonation states were considered in this study, shown in Scheme S1.

Details of the MM molecular dynamics simulations. Before starting any QM/MM simulations, the structure was relaxed by running classical molecular dynamics (MD) using molecular mechanics (MM) force fields in the AMBER software package. ${ }^{5}$ The AMBERFB15 protein force field ${ }^{6}$ and TIP3P-FB water model $^{7}$ were used for the protein and water molecules in the system, the GAFF small molecule force field ${ }^{8}$ was used to model the SAM cofactor, and the Fe-S clusters used a force field model published previously for MD simulations of $[\mathrm{FeFe}]$ hydrogenases. ${ }^{9}$ These force fields are mutually compatible based on past studies that used the Fe-S cluster force field together with AMBER-family force fields, ${ }^{10,11}$ and the high accuracy of AMBER-FB15 and TIP3P-FB when used together. ${ }^{6}$

The MM MD simulations used a simulation time step of 1 fs. Harmonic energy restraints were added to selected interatomic distances in order to ensure the force field does not change the coordination environment around the transition metal centers. The force constant was set to $50 \mathrm{kcal} / \mathrm{mol} / \AA^{2}$ and the restrained distances include the distances between the dangler iron and the atoms coordinated to it (two oxygen atoms from two water molecules, the O, $\mathrm{N}$, and $\mathrm{S}$ atoms from the cysteine ligand, and the $\mathrm{N} \epsilon$ in His265). The cutoff values for shortrange electrostatics and van der Waals interactions were set to $12 \AA$, and the particle-mesh Ewald method was used for long range summation of electrostatic interactions. ${ }^{12}$ Covalent bond lengths involving hydrogen were constrained using the SHAKE algorithm. ${ }^{13}$ A Langevin thermostat algorithm with a collision frequency of $1.0 \mathrm{ps}^{-1}$ was employed for temperature control. In the simulation procedure, energy minimization was carried out first, followed 
by gradual heating from $0 \mathrm{~K}$ to $300 \mathrm{~K}$ using a $200 \mathrm{ps}$ MD simulation at constant volume (NVT), and this was followed by a 200 ps equilibration simulation at constant temperature and pressure (NPT) where a Berendsen barostat was added. Next, a 50 ns MD simulation was carried out under NVT conditions, and the final structure was used as the starting point of hybrid QM/MM simulations.

Hybrid QM/MM simulations at the canonical cluster. The QM/MM simulations were carried out using the Q-Chem and AMBER software packages. ${ }^{5,14,15}$ Due to the complexity of the HydG catalytic reaction, different QM regions were chosen based on which reaction step was studied. Figure S1, left panel shows the selection of QM regions for two reactions occurring at the rSAM Fe-S cluster; in these reaction steps, the broken symmetry approximation was used to model the high spin states and antiferromagnetic coupling of the Fe atoms. Standard electrostatic embedding was applied for the electrostatic interactions between the QM and MM regions, and a pseudo-bond and pseudo-atom approach ${ }^{16}$ was used to treat the covalent bonds between the QM and MM regions.

The QM region was treated using density functional theory (DFT) using the unrestricted B3LYP density functional approximation, which we deemed appropriate for the canonical cluster as the reaction steps here involved mostly organic species. A hybrid basis set was used comprising the LANL2DZ basis set and pseudopotential for Fe atoms and the 6-31G* basis set for all other atoms. The choice of the relatively small basis was necessary in order to enable the QM/MM umbrella sampling described later, which involved running $>10,000$ serial individual calculations. To validate the accuracy of using this basis, we carried out potential energy scans using the larger def-TZVP basis; a comparison of energy profiles shows that the choice of basis set affects the barrier height by $0-2 \mathrm{kcal} / \mathrm{mol}$ (Figure S2).

The QM/MM free energy profiles were generated using an umbrella sampling approach where 15 ps of MD simulations were carried out at multiple windows along the reaction coordinate. The cutoff values for the non-bonded interactions were set to $12 \AA$, and the time step was set to $1 \mathrm{fs}$. In order to compute QM/MM free energy profiles, an umbrella sampling 
approach was adopted. Multiple independent simulations were carried out corresponding to values of the chosen reaction coordinate; in this study most of the spacing between simulations was set to $0.2 \AA$. Individual umbrella sampling runs were modified in order to maximize the thermodynamic overlap between windows while keeping computational cost affordable; 20 windows were used for tyrosine radical generation, 45 windows for the 2-D umbrella sampling of tyrosine decomposition, 20 windows for DHG radical formation, and 12 windows for DHG decomposition.

The initial structures of each umbrella sampling window were determined using a series of constrained energy minimizations. A harmonic potential was added to each simulation to ensure the simulation trajectory remains close to the reaction coordinate. The umbrella sampling QM/MM MD simulations were carried out with an added harmonic potential to ensure the simulation trajectory remains close to the reaction coordinate. The force constants of the harmonic potentials were chosen according to the slope of the energy profile from the constrained minimizations and ranged from 5 to $80 \mathrm{kcal} / \mathrm{mol} / \AA^{2}$. QM/MM MD simulations were carried out for 15 ps for each window, and then the weighted histogram analysis method (WHAM) procedure ${ }^{17,18}$ was used for data in the last 10 ps to determine the free energy profile from the biased trajectories. This procedure produces relative free energies with a statistical error on the order of $1 \mathrm{kcal} / \mathrm{mol}$.

Cluster model calculations at the auxiliary cluster. The reactions at the auxiliary cluster required a greater number of atoms, electrons, and basis functions to be treated simultaneously at the QM level. Because this increased the computational cost significantly, we could not carry out QM/MM umbrella sampling calculations for these reaction steps, and instead used a cluster model that included the atoms shown in blue in Figure S1, right panel. In this model, the dangler $\mathrm{Fe}$ is coordinated to the tridentate cysteine ligand, 5methylimidazole (as a model for the His265 side chain), and two water molecules. The cysteine $\mathrm{S}$ atom bridges the dangler $\mathrm{Fe}$ and the $\mathrm{Fe}_{4} \mathrm{~S}_{4}$ auxiliary cluster, and coordination of cysteine residues to the other three Fe atoms are modeled as MeS (methanethiol) groups. 
To initiate the catalytic cycle, the initial equivalent of $\mathrm{COOH}^{\bullet}$ and $\mathrm{CN}^{-}$ligands are placed in close proximity to the dangler iron. Figure S3 indicates that the dangler Fe is adjacent to a large cavity in the TIM barrel normally occupied by water molecules, indicating there is sufficient space for the movement and reorientation of ligands.

The QM calculations at the auxiliary cluster were carried out using the TeraChem package, ${ }^{19,20}$ which includes graphics processing unit (GPU)-accelerated implementations of density functional theory (DFT) and implicit solvent models. During geometry optimizations, the B3LYP functional and mixed LANL2DZ ECP/6-31G* basis set was adopted, same as the QM/MM calculations. A few optimizations focusing on spin crossover employed the B3LYP* functional $^{21}$ instead, which reduced the percentage of Hartree-Fock exchange from $20 \%$ to $15 \%$ and improved accuracy for spin crossover enthalpies of iron-containing complexes. ${ }^{22}$ After optimizing the geometries, single point energies were computed along the minimum energy pathway to further improve accuracy; these employed a hybrid functional that combines 5\% HF / 95\% B88 exchange and P86 correlation, here called BP86x5, ${ }^{23}$ and a larger triple- $\zeta$ basis set called ma-def2-TZVP(-f)_LTZ+. ${ }^{24}$ This basis combines def2-TZVP ${ }^{25}$ with $l \geq 3$ basis functions removed for non-Fe atoms, augmented by a minimal set of diffuse functions, ${ }^{26}$ and the LANL2TZ+ ECP/basis set for Fe atoms. ${ }^{27}$ Empirical dispersion corrections of the D3(BJ) form were used, adopting the model parameters developed for BP86. ${ }^{28}$ A switching Gaussian polarizable continuum model ${ }^{29-31}$ was used with standard Bondi radii and a dielectric constant of 78.4 (equivalent to water), because we observed the auxiliary cluster in our MM MD simulations to be solvated by 15-20 water molecules.

Equilibrium geometries and transition states were optimized using the geomeTRIC software package, ${ }^{32}$ which uses a translation-rotation internal coordinate system to efficiently optimize the geometries of multi-molecular systems. After optimization of the transition states, an approximate minimum energy path was obtained by minimizing the energy starting from the TS structure along the imaginary mode with step sizes restricted to $<0.01 \AA$. The energy corrections for the TS were obtained the IRCMax approach ${ }^{33}$ by tracing over 
this path with single-point calculations at the BP86x5/ma-def2-TZVP-f_LTZ+ level of theory and choosing the highest energy on the path. The Gibbs free energies of these reaction steps were estimated using vibrational analysis carried out at the reaction endpoints and the transition state and applying the rigid rotor/harmonic oscillator approximation. Although these free energy corrections model the translational entropy using an ideal gas, which is highly approximate and for which numerous corrections have been proposed, ${ }^{34-36}$ we did not find the role of translational entropy to be significant in any reaction steps studied here.

In order to compute standard redox potentials corresponding to electron transfer (ET) and proton-coupled electron transfer (PCET) steps, the free energy change of the reaction was computed in solution. The free energy of the proton at $\mathrm{pH} 0.0$ in aqueous solution was taken to be $-11.803 \mathrm{eV}$, following previous studies, ${ }^{37,38}$ and adjusted to $-11.390 \mathrm{eV}$ by adding $59 \mathrm{meV}$ per $\mathrm{pH}$ unit according to the Nernst equation. The redox potential was then computed as:

$$
E^{\circ}=\frac{\Delta G(\text { reduced - oxidized })}{n F}-4.43 \mathrm{~V}
$$

where $n$ is the number of electrons transferred ( 1 in this study), $F$ is the Faraday constant $\left(1 \mathrm{eV} \mathrm{V}^{-1}\right)$, and $4.43 \mathrm{~V}$ is the absolute potential of the standard hydrogen electrode. ${ }^{39}$ In reactions where a chemical reducing agent (dithionite) was used, the overpotential was computed as $\eta=-\left(E^{\circ}-0.66 \mathrm{~V}\right)$ and the resulting value is converted back to a free energy difference in $\mathrm{kcal} / \mathrm{mol}$, allowing for the inclusion of electrochemical steps on a reaction free energy diagram. ${ }^{40}$

EPR properties, in particular the $g$-tensor and hyperfine tensor $(A)$ eigenvalues, were computed for the structures $\mathbf{5 a}, \mathbf{1 0}$ and $\mathbf{1 1}$ using the ORCA software package. ${ }^{41}$ These calculations used the BP86x5 functional (same as the energies) with the zeroth-order regular relativistic approximation (ZORA) Hamiltonian, ${ }^{42}$ and a mixed basis set consisting of EPR$\mathrm{III}^{43}$ for first-row elements and "ZORA-def2-TZVP" for Fe and S, a recontracted version of def2-TZVP ${ }^{44}$ for ZORA calculations. The RIJCOSX method consisting of density fitting for Coulomb and chain-of-spheres approximation for exchange integrals was employed to speed 
up the calculations. ${ }^{45}$ The $g$-tensor was computed using a coupled-perturbed SCF approach ${ }^{46}$ and the hyperfine values were computed from spin-orbit couplings. ${ }^{47}$ The $3 \mathrm{D}$ structure of 5a was used as-is, whereas the $\mathbf{1 0}$ and $\mathbf{1 1}$ were modified by removing the spectator $\mathrm{CH}_{3} \mathrm{SH}$ and HCN ligands (respectively) and re-optimizing the structure at the BP86x5/def2-SV(P) level of theory.

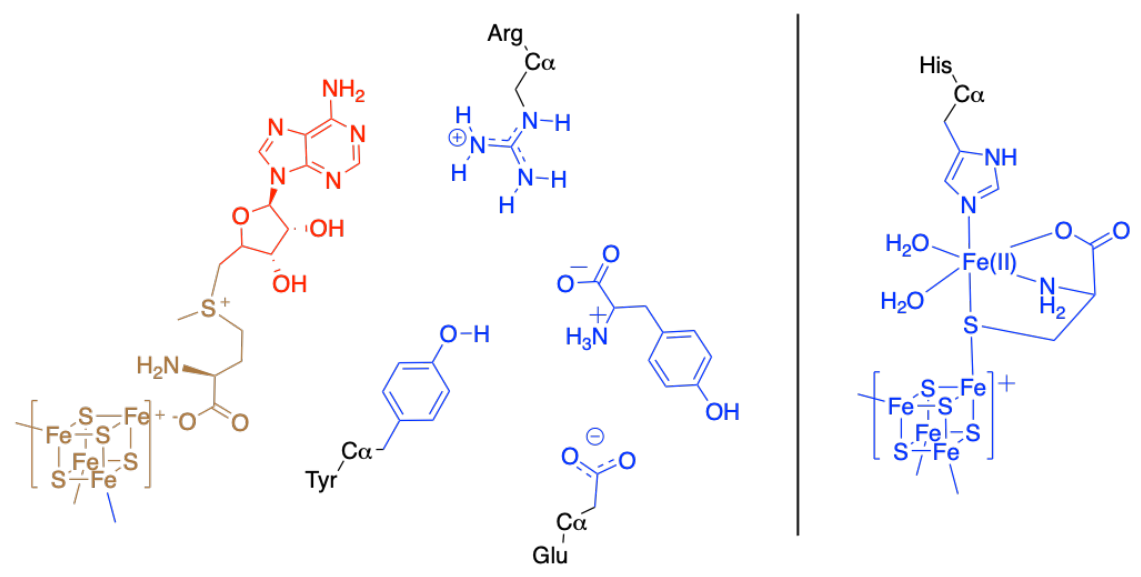

Figure S1: QM regions used for various elementary steps at the rSAM and auxiliary clusters. Left: Atoms shown in brown or red comprise the QM/MM region for the SAM decomposition step, and atoms shown in blue or red comprise the QM/MM region for other reaction steps in the canonical cluster. Right: Atoms in blue comprise the auxiliary cluster model. 


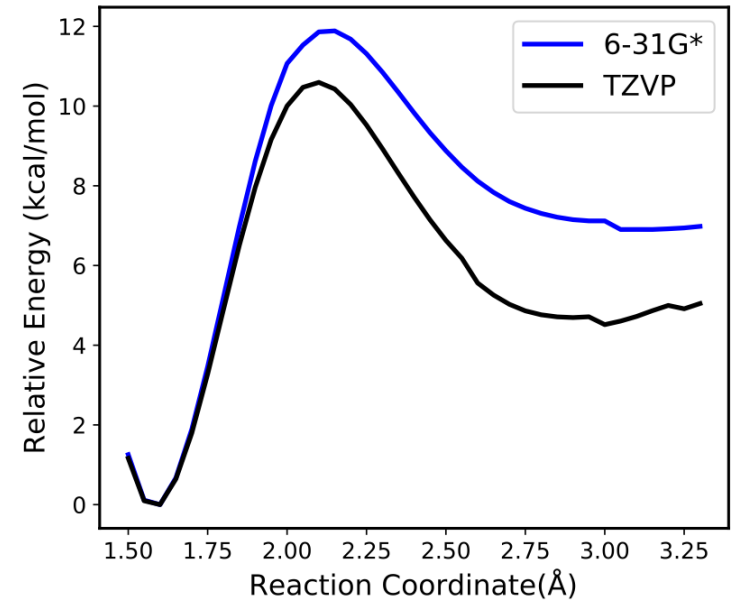

(a)

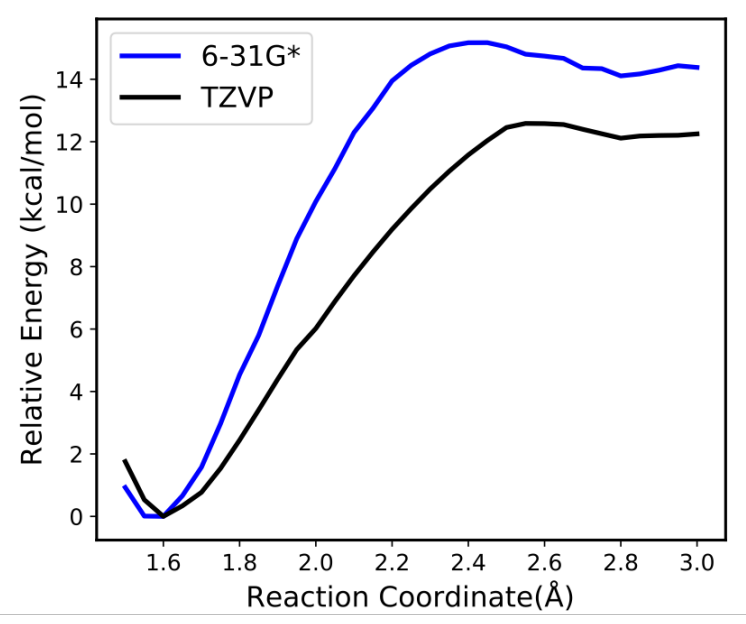

(c)

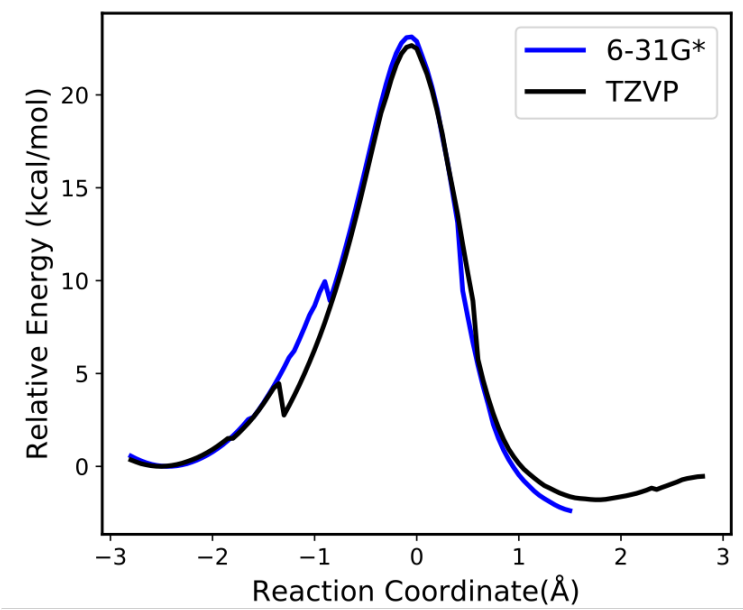

(b)

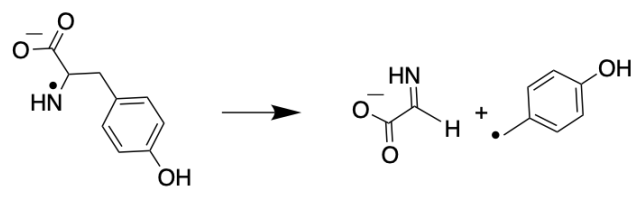

(a) $\mathrm{C} \alpha-\mathrm{C} \beta$ Cleavage<smiles>Cc1ccc(O)cc1</smiles>

(b) DHG Radical Formation

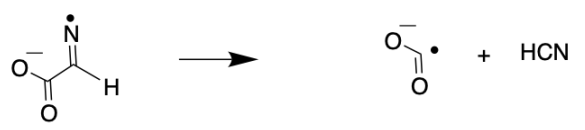

(c) DHG Decomposition

Figure S2: The basis set dependence of the three reactions studied using QM/MM, corresponding to Figures 2-4 in the main text, is investigated by driving the reaction coordinate. The larger def-TZVP basis set (blue curve) predicts barrier heights that are $2 \mathrm{kcal} / \mathrm{mol}$ lower for both the $\mathrm{C} \alpha$-C $\beta$ cleavage (top left) and DHG decomposition reactions (bottom left) compared to the 6-31G* basis used in QM/MM umbrella sampling studies. By contrast, the two basis sets give nearly identical energy profiles in DHG radical formation (top right). Schemes of the reactions are shown at bottom right. 


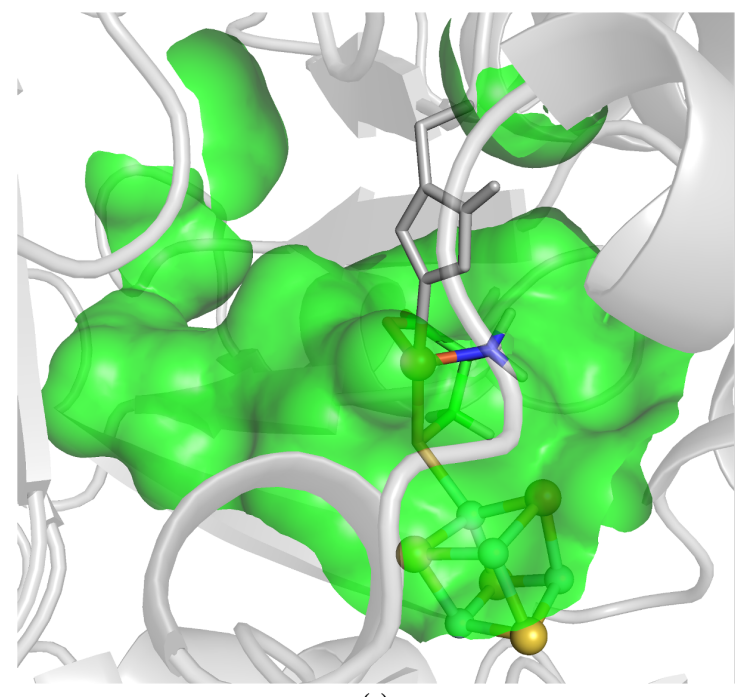

(a)

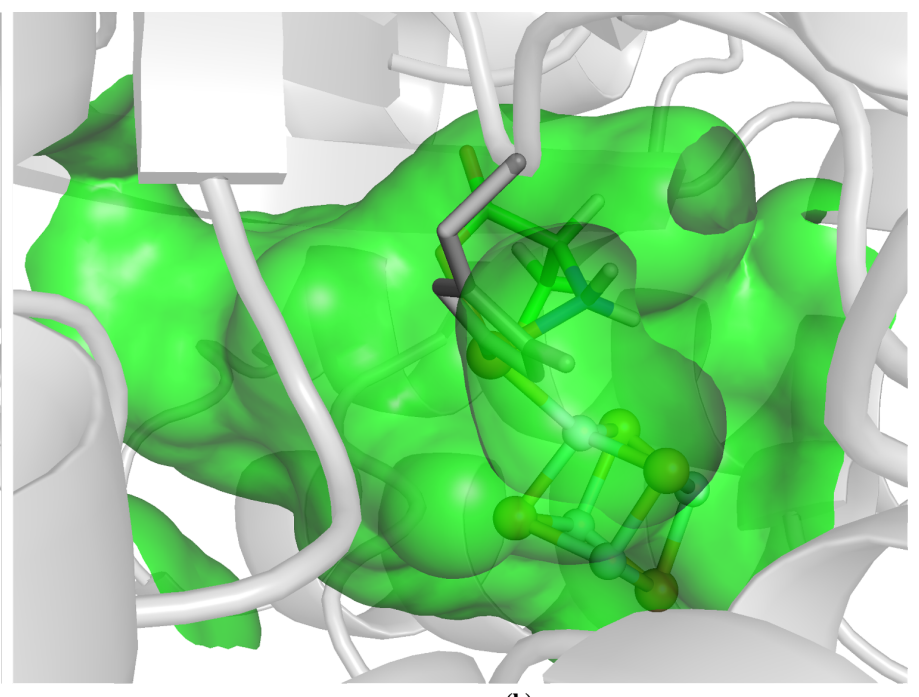

(b)

Figure S3: The position of the auxiliary cluster and dangler Fe at the end of the HydG TIM barrel. The green surface indicates the interior space of the barrel indicating sufficient space for ligand substitutions to be carried out. The solvent-accessible surface is drawn with a probe radius of $1.4 \AA$. 

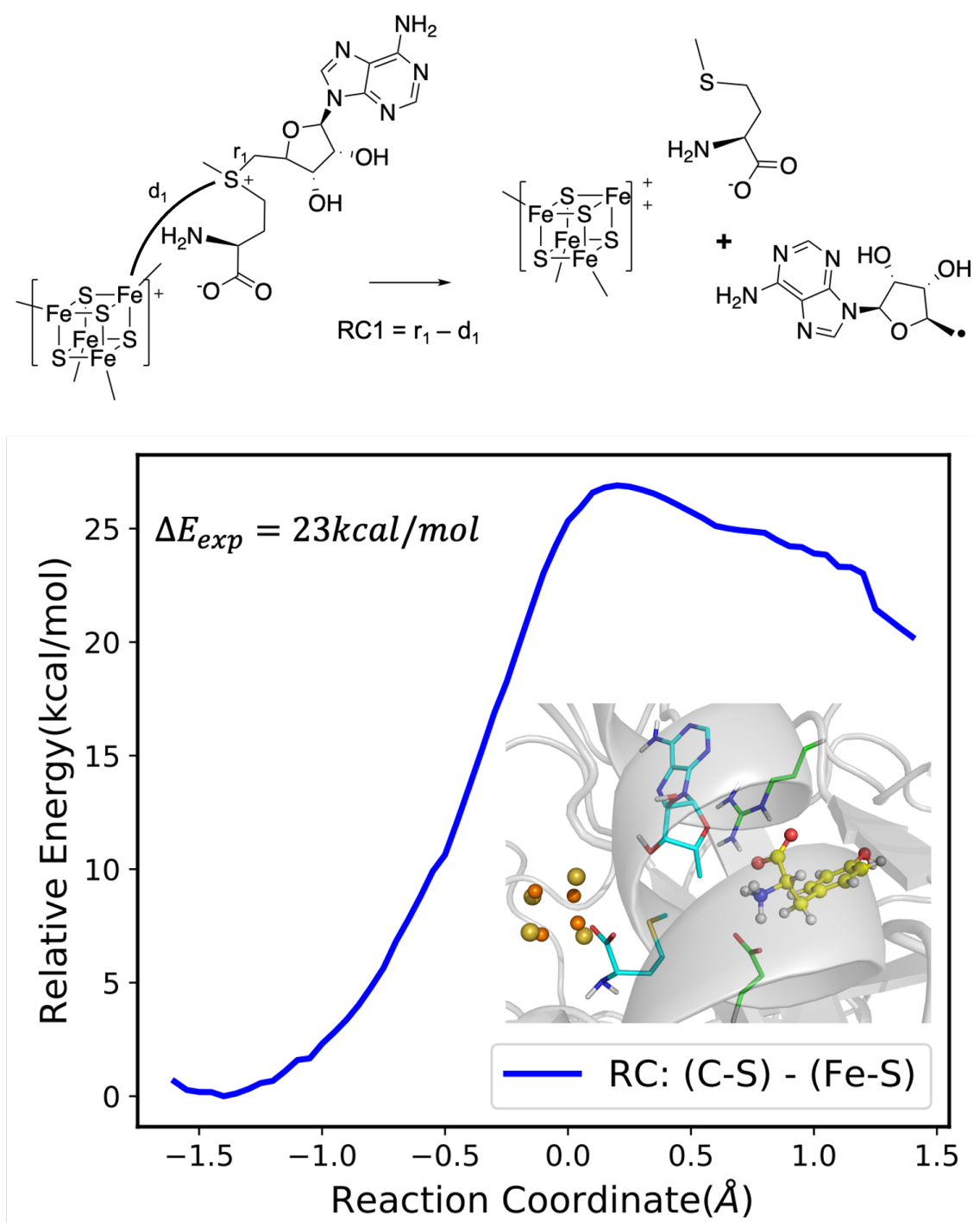

Figure S4: Energy profile of 5-Ado radical generation, generated by driving the reaction coordinate, defined as $\mathrm{RC} 1=\mathrm{d}(\mathrm{C} \ldots \mathrm{S})-\mathrm{d}(\mathrm{Fe} \ldots \mathrm{S})$. Here the activation energy is $\approx 26.3$ $\mathrm{kcal} / \mathrm{mol}$, which is comparable to the experimental data $(23 \mathrm{kcal} / \mathrm{mol})$. 

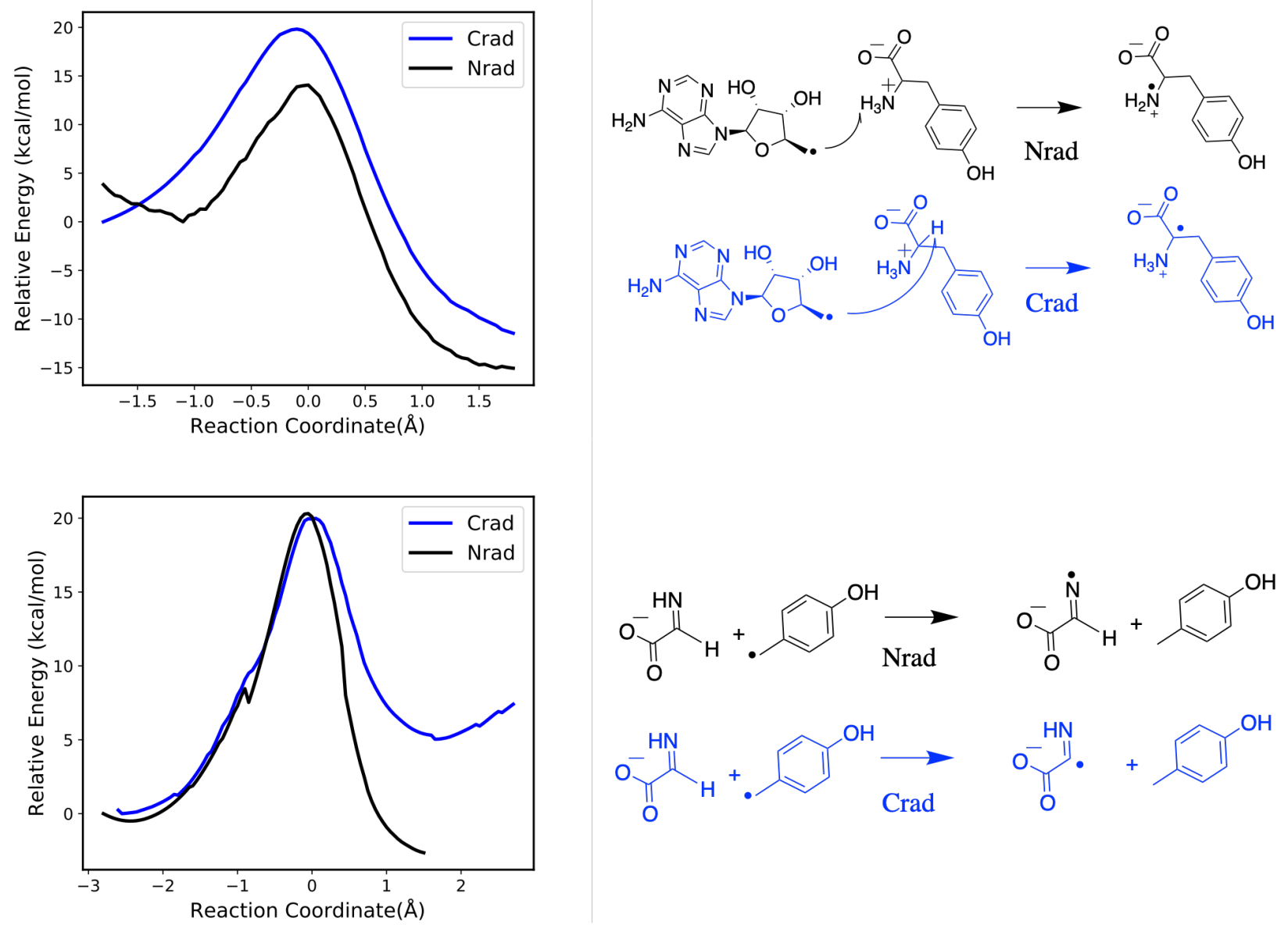<smiles>Cc1ccc(O)cc1</smiles><smiles>CC(C)C(C)(C)C(=O)[CH+]Cc1ccc(O)cc1</smiles><smiles>Cc1ccc(O)cc1</smiles>

Figure S5: Possible alternative pathways in tyrosine radical formation and the DHG radical formation, (the main mechanism is Figure 2 and 4 in the main text respectively). As for the tyrosine radical formation, the experimental data supports the mechanism that the hydrogen abstraction occurred in the amine hydrogen. Here our calculations also support this mechanism since the other possible $\mathrm{H}$ resource, which is the $\mathrm{C} \alpha$, cannot transfer its hydrogen with an energy barrier that as low as the amino group. Regarding the DHG radical formation, the abstraction of the $\mathrm{H}$ from amino group gives a more stable product than that of the $\mathrm{H}$ connected to the sp3 hybridization carbon. 
<smiles>NC(Cc1ccc(O)cc1)C(=O)[O-]</smiles>

TYH<smiles>NC(Cc1ccc(O)cc1)C(=O)O</smiles>

TYY

Scheme 1: Possible protonation states of the tyrosine substrate.
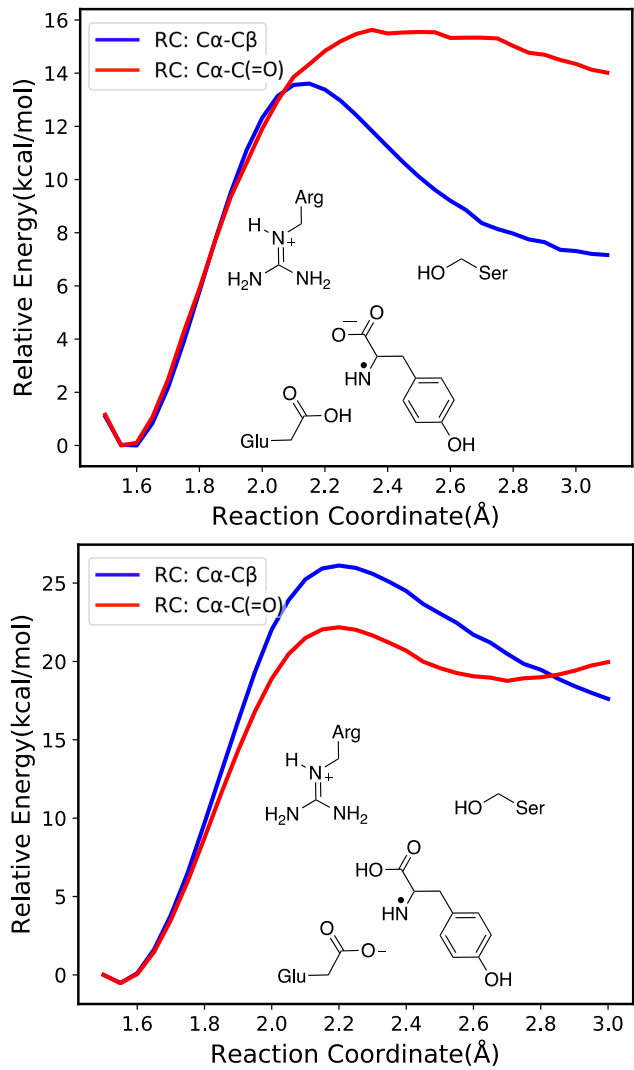

TYH
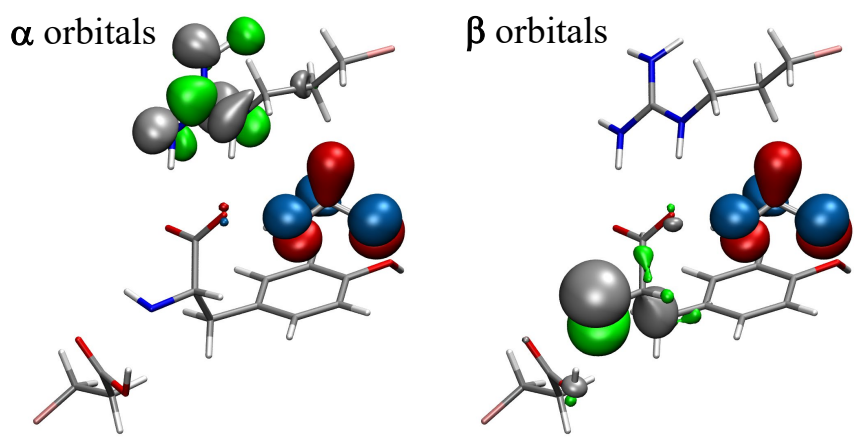

TYY

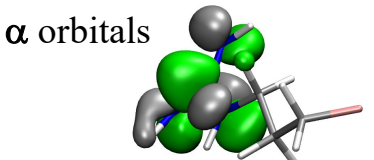

$\beta$ orbitals
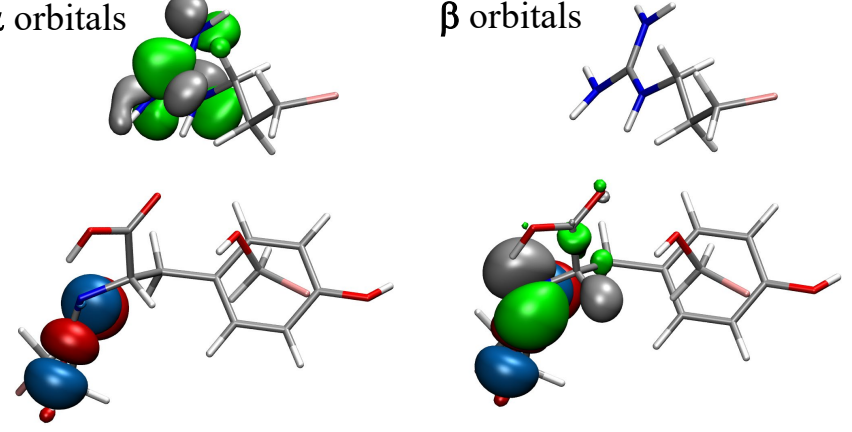

HOMO: red/blue; LUMO: green/silver

Figure S6: Comparison of alternative tyrosine decomposition mechanisms (the main mechanism is Figure 3 in the main text). Two possible protonation states of tyrosine, denoted TYH and TYY, are shown on the top and bottom respectively. To facilitate a direct comparison, we assume the radical $\mathrm{NH}^{\bullet}{ }^{+}$transfers a proton to the Glu side chain prior to to $\mathrm{C}-\mathrm{C}$ cleavage, which could also be observed in our QM/MM simulations. The energy profiles of the two $\mathrm{C}-\mathrm{C}$ cleavage mechanisms for each protonation state are shown on the left; blue curves represent the $\mathrm{C} \alpha-\mathrm{C} \beta$ cleavage and red curves represent the $\mathrm{C} \alpha-\mathrm{C}(=\mathrm{O})$ cleavage. The frontier orbitals of these two tyrosine models are shown on the right. In the TYH model, the LUMO of the $\beta$ electron is shared between the $\mathrm{NH}^{\bullet}$ and the $\mathrm{C} \alpha-\mathrm{C} \beta \sigma$ bond, indicating that the $\mathrm{H}$-atom abstraction may have the effect of weakening the $\mathrm{C} \alpha-\mathrm{C} \beta$ bond order. This correlates with the lowered barrier of $\mathrm{C} \alpha-\mathrm{C} \beta$ cleavage in TYH and is not observed in TYY, where the barrier to $\mathrm{C} \alpha-\mathrm{C} \beta$ cleavage is significantly higher. 
Table S1: The key properties of the various calculated states in the catalytic cycle at the auxiliary cluster. The state labels correspond to Fig. 5 and Fig. 6 in the main text. The charge and spin multiplicity given is for the whole calculated system, including any added $\mathrm{COOH}^{\bullet}$ and $\mathrm{CN}^{-}$ligands. The state labeled 10 is actually two calculations consisting of a synthon fragment and $\mathrm{Fe}_{4} \mathrm{~S}_{4}-\mathrm{CN}$ fragment labeled 10.S and 10.C respectively.

\begin{tabular}{|l|l|l|l|l|l|l|}
\hline $\begin{array}{l}\text { State } \\
\text { Label }\end{array}$ & Charge & $\begin{array}{l}\text { Spin } \\
\text { Mult. }\end{array}$ & $\begin{array}{l}\mathrm{Fe}_{4} \mathrm{~S}_{4} \\
\text { State }\end{array}$ & Dangler Fe State & $\mathrm{N}\left(\mathrm{COOH}^{\bullet}\right)$ & $\mathrm{N}\left(\mathrm{CN}^{-}\right)$ \\
\hline 1 & -3 & 5 & + & $\mathrm{Fe}(\mathrm{II})(\mathrm{Cys})(5-\mathrm{MIm})\left(\mathrm{H}_{2} \mathrm{O}\right)_{2}$ & 1 & 1 \\
\hline 2 & -3 & 1 & + & $\mathrm{Fe}(\mathrm{II})(\mathrm{Cys})(5-\mathrm{MIm})(\mathrm{CN})\left(\mathrm{H}_{2} \mathrm{O}\right)$ & 1 & 1 \\
\hline 3 & -3 & 1 & $2+$ & $\mathrm{Fe}(\mathrm{II})(\mathrm{Cys})(5-\mathrm{MIm})(\mathrm{CN})(\mathrm{COOH})$ & 1 & 1 \\
\hline 4 & -2 & 1 & $2+$ & $\mathrm{Fe}(\mathrm{II})\left(\mathrm{CysH}^{+}\right)(5-\mathrm{MIm})(\mathrm{CN})(\mathrm{COOH})$ & 1 & 1 \\
\hline 5 & -2 & 1 & $2+$ & $\mathrm{Fe}(\mathrm{II})(\mathrm{Cys})(5-\mathrm{MIm})(\mathrm{CN})(\mathrm{CO})$ & 1 & 1 \\
\hline $4 \mathrm{a}$ & -3 & 2 & + & $\mathrm{Fe}(\mathrm{II})\left(\mathrm{CysH}^{+}\right)(5-\mathrm{MIm})(\mathrm{CN})(\mathrm{COOH})$ & 1 & 1 \\
\hline $5 \mathrm{a}$ & -3 & 2 & + & $\mathrm{Fe}(\mathrm{II})(\mathrm{Cys})(5-\mathrm{MIm})(\mathrm{CN})(\mathrm{CO})$ & 1 & 1 \\
\hline 6 & -3 & 1 & + & $\mathrm{Fe}(\mathrm{III})\left(\mathrm{Cys}^{\prime}(5-\mathrm{MIm})(\mathrm{CN})(\mathrm{COCOOH})\right.$ & 2 & 1 \\
\hline 7 & -2 & 1 & $2+$ & $\left.\mathrm{Fe}(\mathrm{II})(\mathrm{CysH})^{+}\right)(5-\mathrm{MIm})(\mathrm{CN})(\mathrm{COCOOH})$ & 2 & 1 \\
\hline 8 & -2 & 1 & $2+$ & $\mathrm{Fe}(\mathrm{II})(\mathrm{Cys})(5-\mathrm{MIm})(\mathrm{CN})(\mathrm{CO})$ & 2 & 1 \\
\hline $7 \mathrm{a}$ & -3 & 2 & + & $\left.\mathrm{Fe}(\mathrm{II})(\mathrm{CysH})^{+}\right)(5-\mathrm{MIm})(\mathrm{CN})(\mathrm{COCOOH})$ & 2 & 1 \\
\hline $8 \mathrm{a}$ & -3 & 2 & + & $\mathrm{Fe}(\mathrm{II})(\mathrm{Cys})(5-\mathrm{MIm})(\mathrm{CN})(\mathrm{CO})$ & 2 & 1 \\
\hline 9 & -3 & 2 & + & $\mathrm{Fe}(\mathrm{II})(\mathrm{Cys})(\mathrm{CN})(\mathrm{CO})_{2}$ & 2 & 1 \\
\hline 10 & -4 & 2 & + & $\mathrm{Fe}(\mathrm{II})(\mathrm{Cys})(\mathrm{CN})(\mathrm{CO})_{2}$ & 2 & 2 \\
\hline $10 . \mathrm{S}$ & -1 & 1 & $\mathrm{~N} / \mathrm{A}$ & $\mathrm{Fe}(\mathrm{II})(\mathrm{Cys})(\mathrm{CN})(\mathrm{CO})_{2}$ & 2 & 1 \\
\hline $10 . \mathrm{C}$ & -3 & 2 & + & $\mathrm{N} / \mathrm{A}$ & 0 & 1 \\
\hline 11 & -3 & 2 & + & $\mathrm{N} / \mathrm{A}$ & 0 & 1 \\
\hline
\end{tabular}



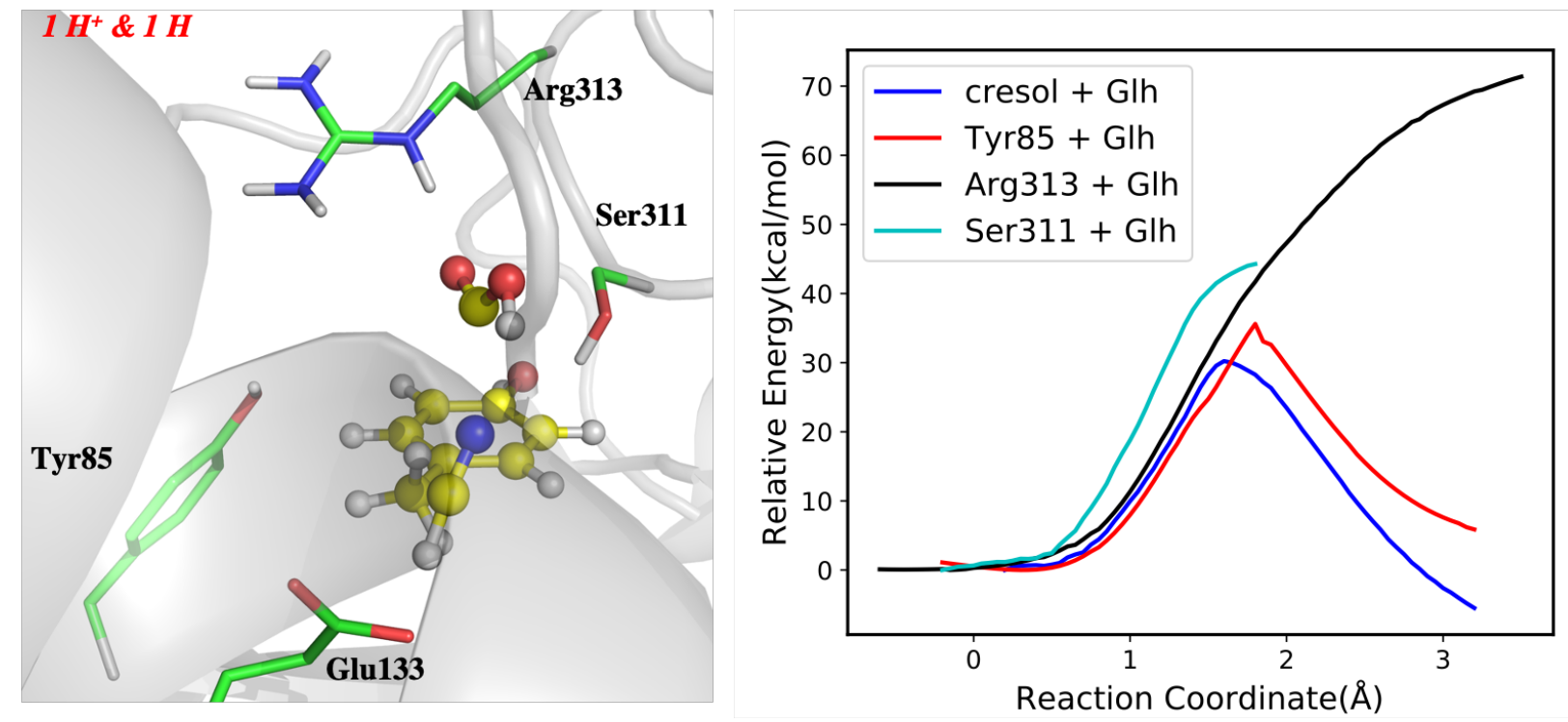

Figure S7: Several possible pathways of the reduction of $\mathrm{COOH}$ radical to $\mathrm{CO}$ in the canonical $\mathrm{rSAM} \mathrm{Fe}_{4} \mathrm{~S}_{4}$ cluster pocket. All of the activation energies are in excess of $30 \mathrm{kcal} / \mathrm{mol}$, which indicates that $\mathrm{COOH}$ does not decompose in the cluster pocket. Instead we propose that $\mathrm{COOH}^{\bullet}$ diffuses to the auxiliary cluster where reduction to $\mathrm{CO}$ occurs at the dangler iron. 


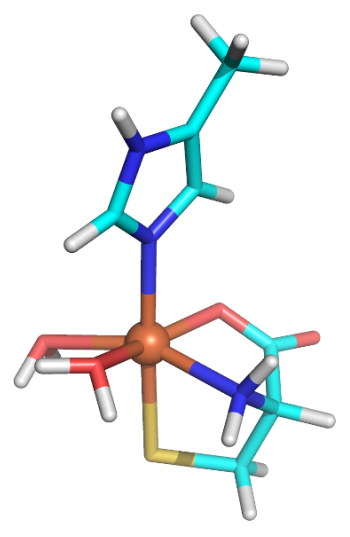

$\mathrm{Fe}(\mathrm{Wat})_{2}$

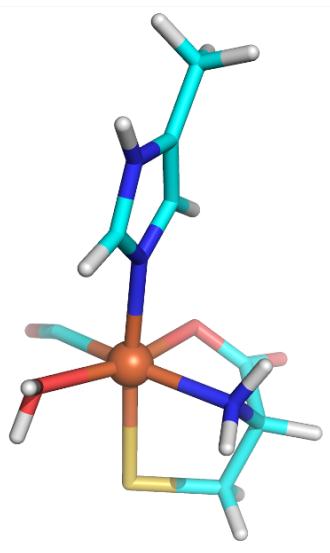

$\mathrm{Fe}(\mathrm{CO})(\mathrm{Wat})$

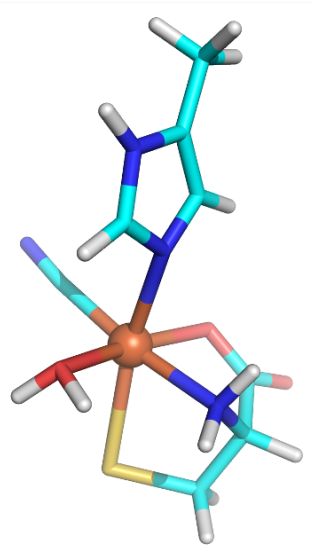

$\mathrm{Fe}(\mathrm{CN})(\mathrm{Wat})$

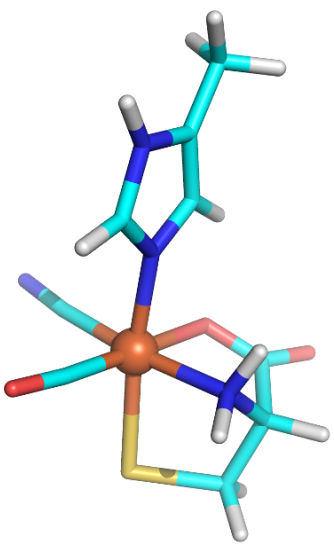

$\mathrm{Fe}(\mathrm{CN})(\mathrm{CO})$

Figure S8: Structures of the Fe(cys)(5-MIm) complex used in the multireference DMRG studies.

Table S2: The energy differences between different iron cluster structures calculated by density matrix renormalization group (DMRG).

\begin{tabular}{|c|c|c|c|c|}
\hline & $\mathrm{Fe}\left(\mathrm{H}_{2} \mathrm{O}\right)_{2}$ & $\mathrm{Fe}(\mathrm{CO})\left(\mathrm{H}_{2} \mathrm{O}\right)$ & $\mathrm{Fe}(\mathrm{CN})\left(\mathrm{H}_{2} \mathrm{O}\right)$ & $\mathrm{Fe}(\mathrm{CO})(\mathrm{CN})$ \\
\hline \hline Active Space & $(20,18)$ & $(20,18)$ & $(20,18)$ & $(22,20)$ \\
\hline E(HS)-E(LS) & -68.2 & 28.3 & 25.1 & 50.2 \\
\hline
\end{tabular}

Multireference DMRG calculation methods. All four structures were optimized under B3LYP//6-31G*/LANL2DZ(Fe) in Q-Chem, and the DMRG single point energies were calculated using the TZV basis set in PySCF. The active spaces in the calculations were selected from localized molecular orbitals by including the five orbitals with $3 d$ character on the Fe atom and the orbitals with $p$ character on the coordinating ligands $(2 p$ for $\mathrm{O}, \mathrm{C}, \mathrm{N}$ and $3 p$ for $\mathrm{S}$ ) that had an overlap integral of $>0.3$ with any of the $d$ orbitals; the orbital selections were then confirmed by visual inspection of isosurface plots. The total number of orbitals and electrons in the DMRG calculations is provided in the table above as (active electrons, active orbitals). The bond dimension of the DMRG calculations is set to 1000, and the number of sweeps is set to the default value of 4 . Energies are in units of kcal $/ \mathrm{mol}$. 

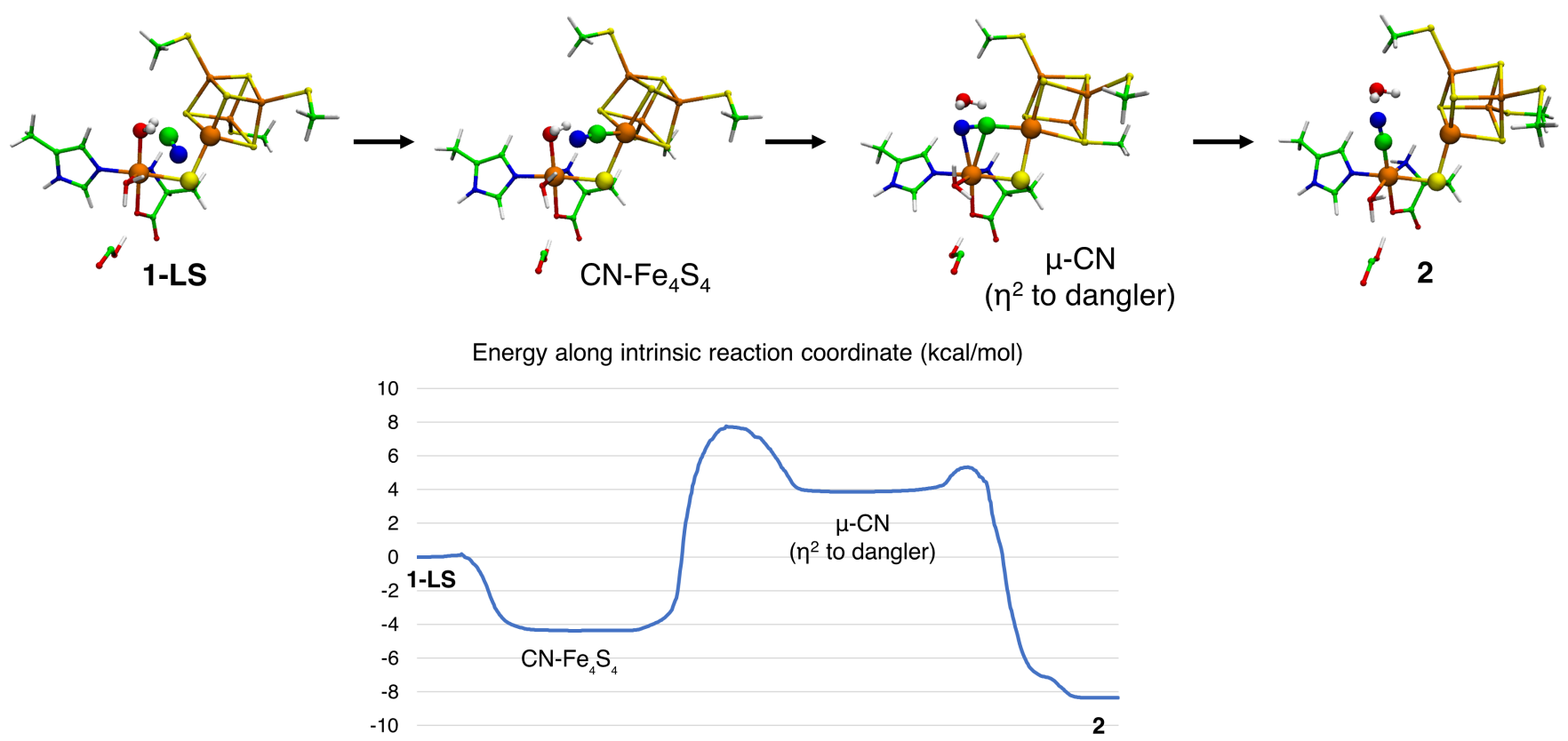

Figure S9: 3D renderings and plot of electronic energies (B3LYP/6-31G*_LANL2DZ/PCM) along the minimum energy path of the reaction 1-LS $+\mathrm{CN}^{-} \rightarrow \mathbf{2}+\mathrm{H}_{2} \mathrm{O}$ where a $\mathrm{CN}^{-}$ligand displaces an aquo ligand. A spectator $\mathrm{COOH}^{\bullet}$ species is present in the system.

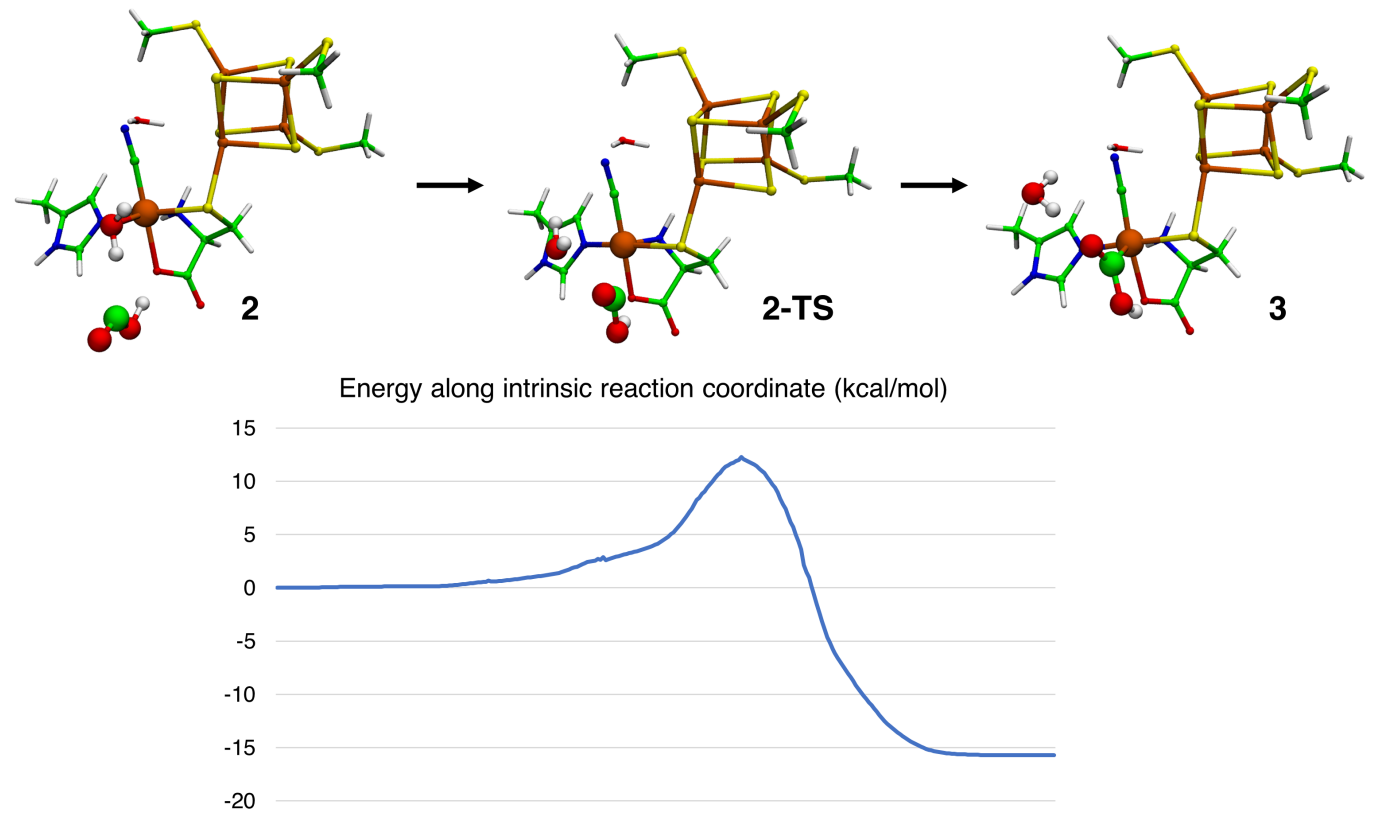

Figure S10: 3D renderings and plot of electronic energies (B3LYP/6-31G*_LANL2DZ/PCM) along the minimum energy path of the reaction $\mathbf{2}-\mathbf{L S}+\mathrm{COOH}^{\bullet} \rightarrow \mathbf{3}+\mathrm{H}_{2} \mathrm{O}$ where $\mathrm{COOH}^{\bullet}$ displaces the second aquo ligand. Following this, $\mathbf{3}$ is protonated to form $\mathbf{4}$. 


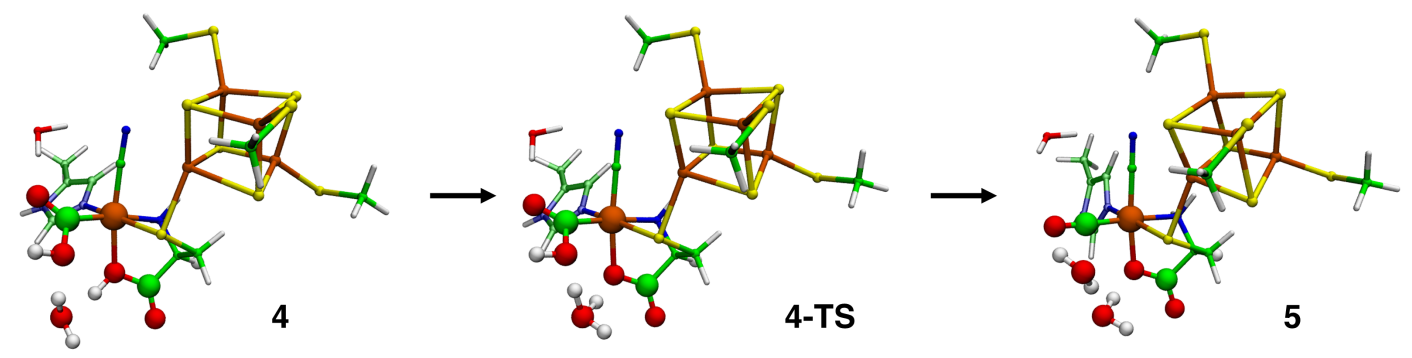

Energy along intrinsic reaction coordinate $(\mathrm{kcal} / \mathrm{mol})$

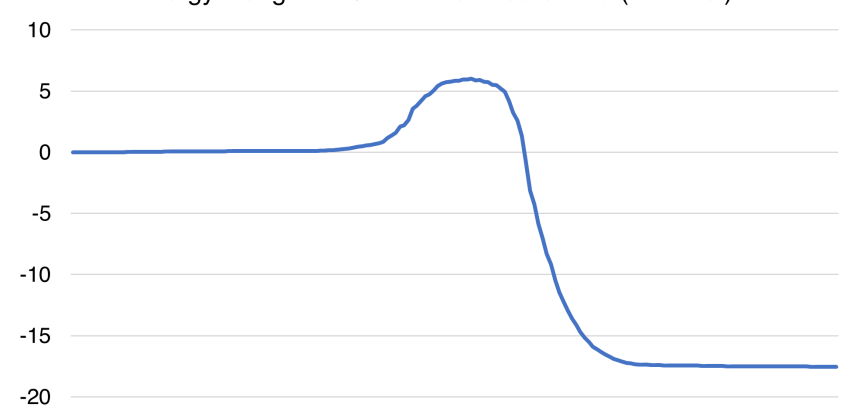

Figure S11: 3D renderings and plot of electronic energies (B3LYP/6-31G*_LANL2DZ/PCM) along the minimum energy path of the reaction $\mathbf{4} \rightarrow \mathbf{5}+\mathrm{H}_{2} \mathrm{O}$ where the $\mathrm{COOH}$ ligand accepts a proton from the cysteine oxygen, then is decomposed to $\mathrm{CO}$ and $\mathrm{H}_{2} \mathrm{O}$.

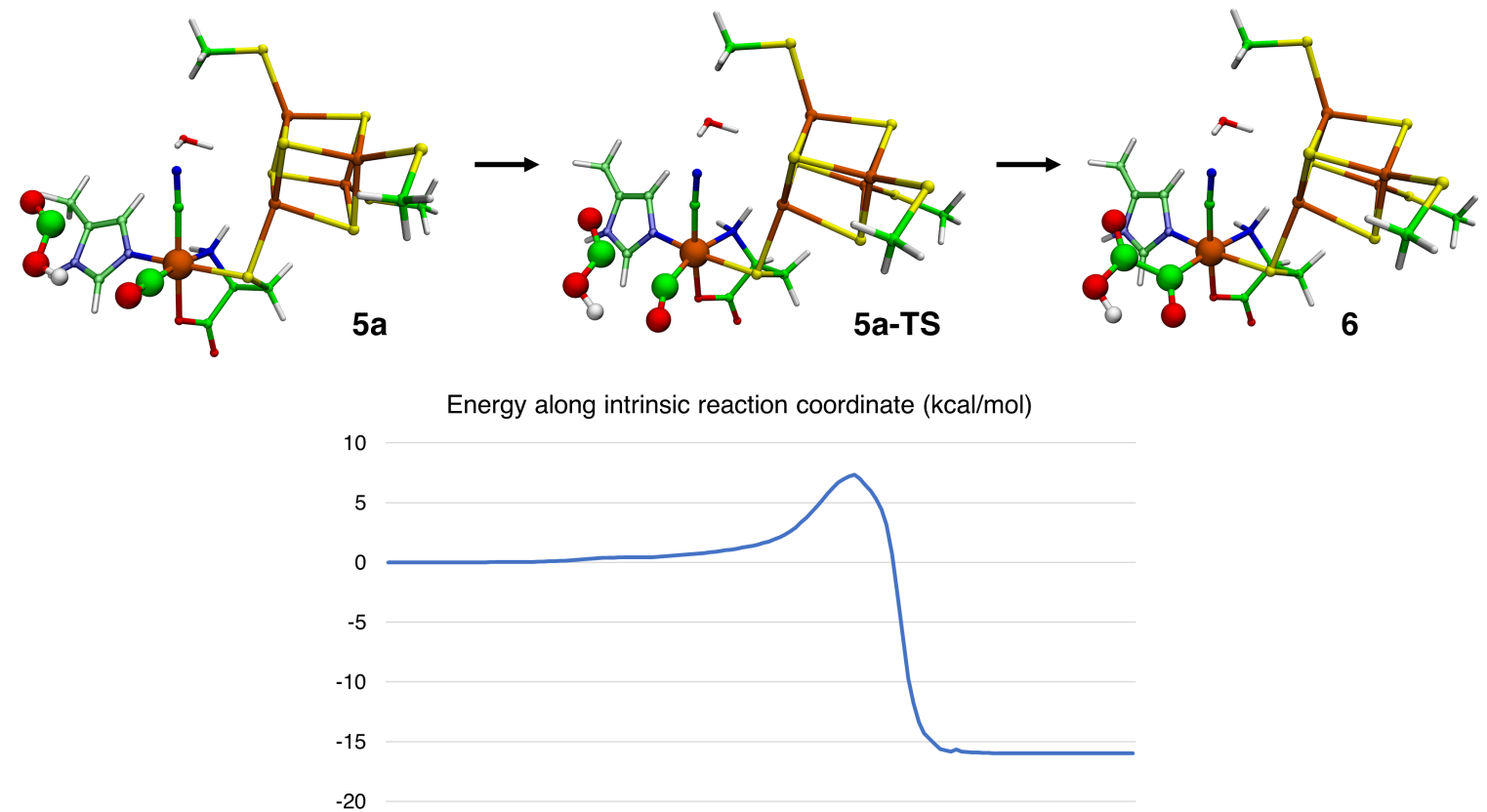

Figure S12: 3D renderings and plot of electronic energies (B3LYP/6-31G*_LANL2DZ/PCM) along the minimum energy path of the reaction $\mathbf{5 a}+\mathrm{COOH}^{\bullet} \rightarrow \mathbf{6}$ where the added $\mathrm{COOH}^{\bullet}$ forms a $\mathrm{C}-\mathrm{C}$ bond with the first $\mathrm{CO}$ ligand to form a $\mathrm{COCOOH}$ ligand to the dangler Fe. Following this, $\mathbf{6}$ is protonated to form $\mathbf{7}$. 


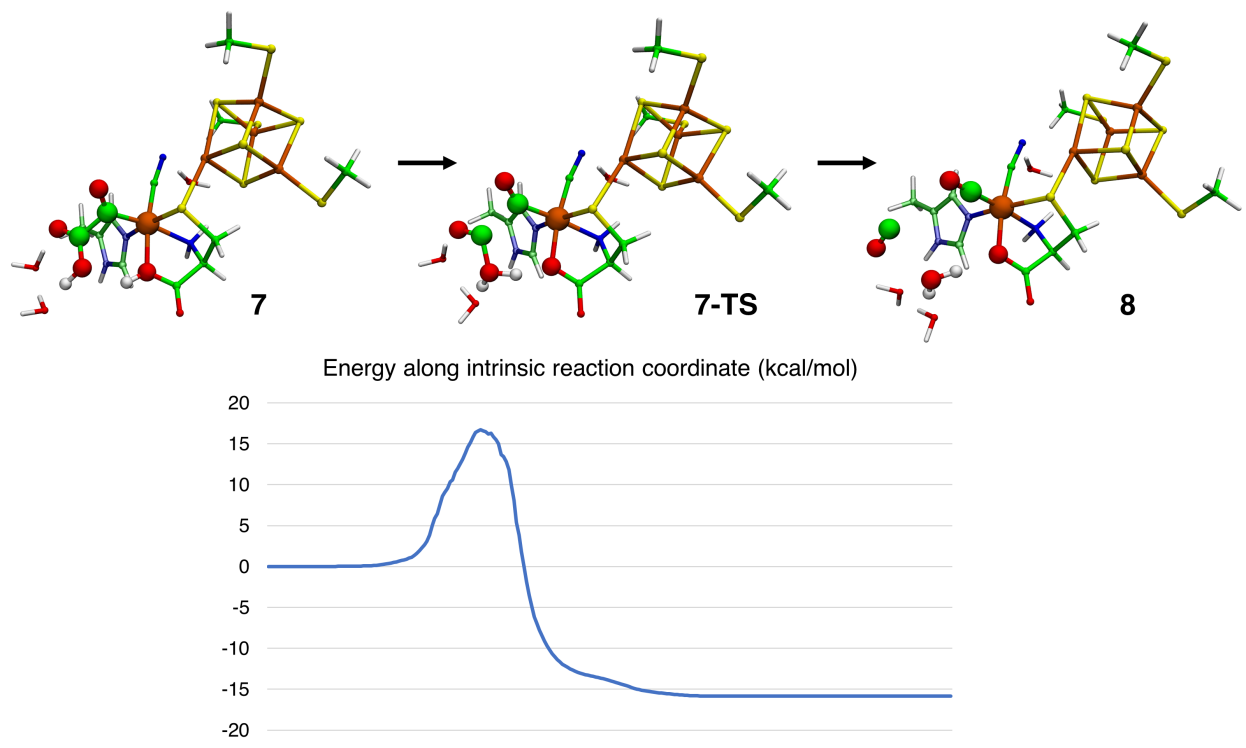

Figure S13: 3D renderings and plot of electronic energies (B3LYP/6-31G*_LANL2DZ/PCM) along the minimum energy path of the reaction $\mathbf{7} \rightarrow \mathbf{8}+\mathrm{CO}+\mathrm{H}_{2} \mathrm{O}$ where the $\mathrm{COCOOH}$ ligand accepts a proton from the cysteine oxygen, then is decomposed to a free $\mathrm{CO}+\mathrm{CO}$ ligand $+\mathrm{H}_{2} \mathrm{O}$.
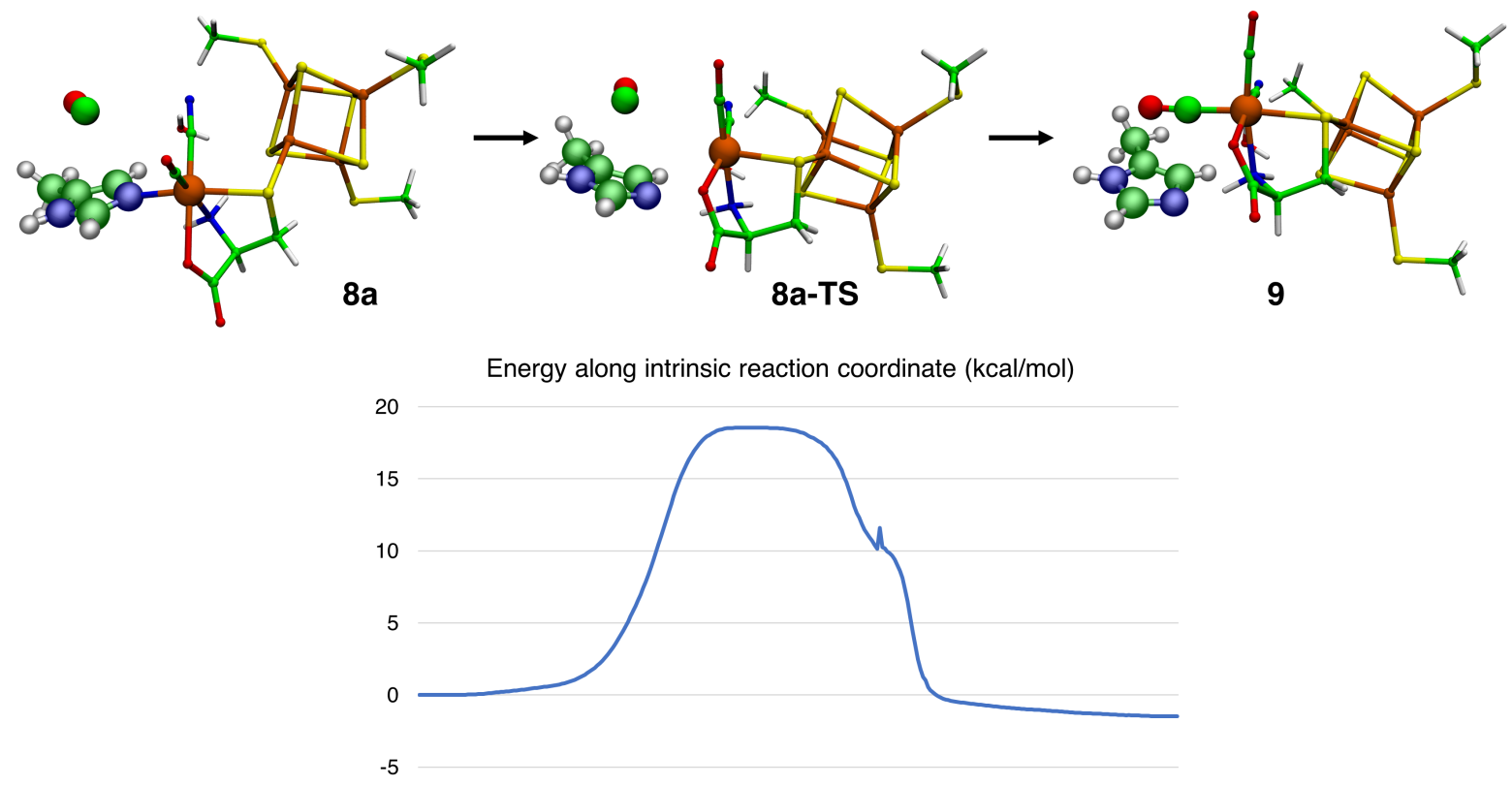

Figure S14: 3D renderings and plot of electronic energies (B3LYP/6-31G*_LANL2DZ/PCM) along the minimum energy path of the reaction $\mathbf{8}+\mathrm{CO} \rightarrow \mathbf{9}+5$-MIm where the second $\mathrm{CO}$ displaces the 5-methylimidazole ligand. 

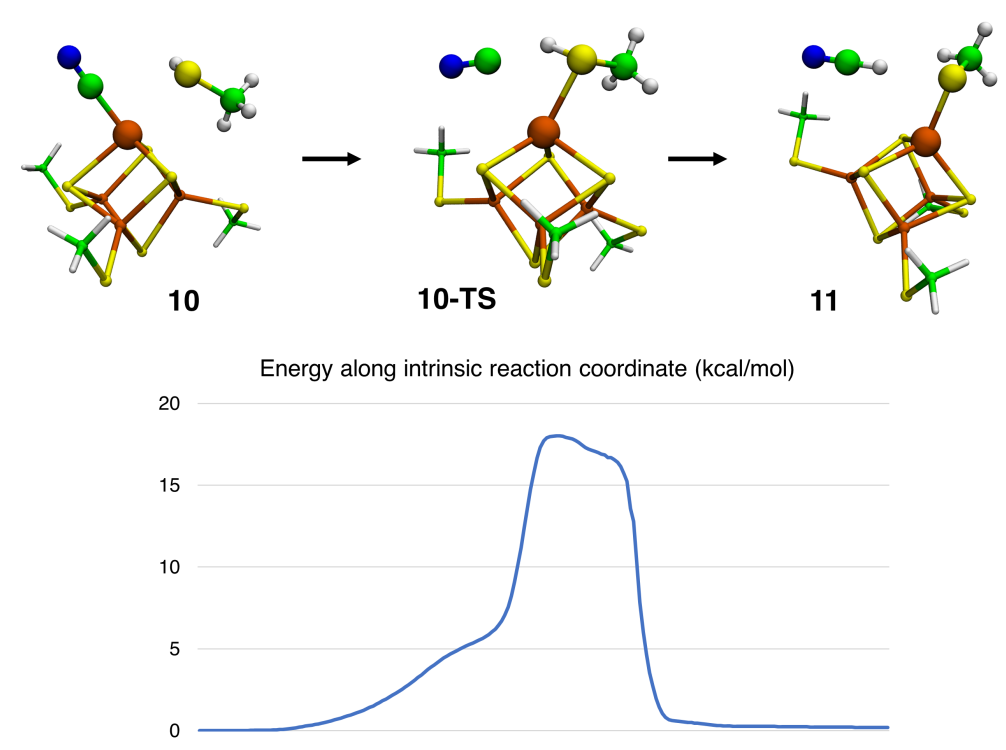

Figure S15: 3D renderings and plot of electronic energies (B3LYP/6-31G*_LANL2DZ/PCM) along the minimum energy path of the reaction $\mathbf{1 0}+\mathrm{CH}_{3} \mathrm{SH} \rightarrow \mathbf{1 1}+\mathrm{HCN}$ where a $\mathrm{CH}_{3} \mathrm{SH}$ model of the cysteine side chain displaces the $\mathrm{CN}$ ligand to the auxiliary cluster, releasing $\mathrm{HCN}$ and turning over the catalytic cycle.

\section{References}

(1) Dinis, P.; Suess, D. L.; Fox, S. J.; Harmer, J. E.; Driesener, R. C.; De La Paz, L.; Swartz, J. R.; Essex, J. W.; Britt, R. D.; Roach, P. L. X-ray crystallographic and EPR spectroscopic analysis of HydG, a maturase in [FeFe]-hydrogenase H-cluster assembly. Proceedings of the National Academy of Sciences 2015, 112, 1362-1367.

(2) Suess, D. L.; Bürstel, I.; De La Paz, L.; Kuchenreuther, J. M.; Pham, C. C.; Cramer, S. P.; Swartz, J. R.; Britt, R. D. Cysteine as a ligand platform in the biosynthesis of the FeFe hydrogenase H cluster. Proceedings of the National Academy of Sciences 2015, 112, 11455-11460.

(3) Nicolet, Y.; Zeppieri, L.; Amara, P.; Fontecilla-Camps, J. C. Crystal structure of tryp- 
tophan lyase (NosL): evidence for radical formation at the amino group of tryptophan. Angewandte Chemie International Edition 2014, 53, 11840-11844.

(4) Morris, G. M.; Huey, R.; Lindstrom, W.; Sanner, M. F.; Belew, R. K.; Goodsell, D. S.; Olson, A. J. AutoDock4 and AutoDockTools4: Automated docking with selective receptor flexibility. Journal of computational chemistry 2009, 30, 2785-2791.

(5) Case, D.; Belfon, K.; Ben-Shalom, I.; Brozell, S.; Cerutti, D.; T.E. Cheatham, I.; Cruzeiro, V.; Darden, T.; Duke, R.; Giambasu, G.; Gilson, M.; Gohlke, H.; Goetz, A.; Harris, R.; Izadi, S.; Izmailov, S.; Kasavajhala, K.; Kovalenko, A.; Krasny, R.; Kurtzman, T.; Lee, T.; LeGrand, S.; Li, P.; Lin, C.; Liu, J.; Luchko, T.; Luo, R.; Man, V.; Merz, K.; Miao, Y.; Mikhailovskii, O.; Monard, G.; Nguyen, H.; Onufriev, A.; F.Pan,; Pantano, S.; Qi, R.; Roe, D.; Roitberg, A.; Sagui, C.; Schott-Verdugo, S.; Shen, J.; Simmerling, C.; N.R.Skrynnikov,; Smith, J.; Swails, J.; Walker, R.; Wang, J.; Wilson, L.; Wolf, R.; Wu, X.; Xiong, Y.; Xue, Y.; York, D.; Kollman, P. AMBER 2020, University of California, San Francisco.

(6) Wang, L.-P.; McKiernan, K. A.; Gomes, J.; Beauchamp, K. A.; Head-Gordon, T.; Rice, J. E.; Swope, W. C.; Martínez, T. J.; Pande, V. S. Building a more predictive protein force field: a systematic and reproducible route to AMBER-FB15. The Journal of Physical Chemistry B 2017, 121, 4023-4039.

(7) Wang, L.-P.; Martinez, T. J.; Pande, V. S. Building Force Fields: An Automatic, Systematic, and Reproducible Approach. The Journal of Physical Chemistry Letters 2014, 5, 1885-1891.

(8) Wang, J.; Wolf, R. M.; Caldwell, J. W.; Kollman, P. A.; Case, D. A. Development and testing of a general amber force field. Journal of Computational Chemistry 2004, 25, $1157-1174$.

(9) Chang, C. H.; Kim, K. Density functional theory calculation of bonding and charge 
parameters for molecular dynamics studies on [FeFe] hydrogenases. Journal of chemical theory and computation 2009, 5, 1137-1145.

(10) Long, H.; King, P. W.; Chang, C. H. Proton transport in Clostridium pasteurianum [FeFe] hydrogenase I: a computational study. The Journal of Physical Chemistry B 2014, 118, 890-900.

(11) Kubas, A.; Orain, C.; De Sancho, D.; Saujet, L.; Sensi, M.; Gauquelin, C.; MeynialSalles, I.; Soucaille, P.; Bottin, H.; Baffert, C., et al. Mechanism of O 2 diffusion and reduction in FeFe hydrogenases. Nature chemistry 2017, 9, 88-95.

(12) Essmann, U.; Perera, L.; Berkowitz, M. L.; Darden, T.; Lee, H.; Pedersen, L. G. A smooth particle mesh Ewald method. The Journal of Chemical Physics 1995, 103, $8577-8593$.

(13) Andersen, H. C. Rattle: A "velocity" version of the shake algorithm for molecular dynamics calculations. Journal of Computational Physics 1983, 52, 24-34.

(14) Shao, Y.; Gan, Z.; Epifanovsky, E.; Gilbert, A. T.; Wormit, M.; Kussmann, J.; Lange, A. W.; Behn, A.; Deng, J.; Feng, X.; Ghosh, D.; Goldey, M.; Horn, P. R.; Jacobson, L. D.; Kaliman, I.; Khaliullin, R. Z.; Kuś, T.; Landau, A.; Liu, J.; Proynov, E. I.; Rhee, Y. M.; Richard, R. M.; Rohrdanz, M. A.; Steele, R. P.; Sundstrom, E. J.; III, H. L. W.; Zimmerman, P. M.; Zuev, D.; Albrecht, B.; Alguire, E.; Austin, B.; Beran, G. J. O.; Bernard, Y. A.; Berquist, E.; Brandhorst, K.; Bravaya, K. B.; Brown, S. T.; Casanova, D.; Chang, C.-M.; Chen, Y.; Chien, S. H.; Closser, K. D.; Crittenden, D. L.; Diedenhofen, M.; Jr., R. A. D.; Do, H.; Dutoi, A. D.; Edgar, R. G.; Fatehi, S.; Fusti-Molnar, L.; Ghysels, A.; Golubeva-Zadorozhnaya, A.; Gomes, J.; Hanson-Heine, M. W.; Harbach, P. H.; Hauser, A. W.; Hohenstein, E. G.; Holden, Z. C.; Jagau, T.-C.; Ji, H.; Kaduk, B.; Khistyaev, K.; Kim, J.; Kim, J.; King, R. A.; Klunzinger, P.; Kosenkov, D.; Kowalczyk, T.; Krauter, C. M.; Lao, K. U.; Laurent, A. D.; 
Lawler, K. V.; Levchenko, S. V.; Lin, C. Y.; Liu, F.; Livshits, E.; Lochan, R. C.; Luenser, A.; Manohar, P.; Manzer, S. F.; Mao, S.-P.; Mardirossian, N.; Marenich, A. V.; Maurer, S. A.; Mayhall, N. J.; Neuscamman, E.; Oana, C. M.; Olivares-Amaya, R.; O’Neill, D. P.; Parkhill, J. A.; Perrine, T. M.; Peverati, R.; Prociuk, A.; Rehn, D. R.; Rosta, E.; Russ, N. J.; Sharada, S. M.; Sharma, S.; Small, D. W.; Sodt, A.; Stein, T.; Stück, D.; Su, Y.-C.; Thom, A. J.; Tsuchimochi, T.; Vanovschi, V.; Vogt, L.; Vydrov, O.; Wang, T.; Watson, M. A.; Wenzel, J.; White, A.; Williams, C. F.; Yang, J.; Yeganeh, S.; Yost, S. R.; You, Z.-Q.; Zhang, I. Y.; Zhang, X.; Zhao, Y.; Brooks, B. R.; Chan, G. K.; Chipman, D. M.; Cramer, C. J.; III, W. A. G.; Gordon, M. S.; Hehre, W. J.; Klamt, A.; III, H. F. S.; Schmidt, M. W.; Sherrill, C. D.; Truhlar, D. G.; Warshel, A.; Xu, X.; Aspuru-Guzik, A.; Baer, R.; Bell, A. T.; Besley, N. A.; Chai, J.-D.; Dreuw, A.; Dunietz, B. D.; Furlani, T. R.; Gwaltney, S. R.; Hsu, C.-P.; Jung, Y.; Kong, J.; Lambrecht, D. S.; Liang, W.; Ochsenfeld, C.; Rassolov, V. A.; Slipchenko, L. V.; Subotnik, J. E.; Voorhis, T. V.; Herbert, J. M.; Krylov, A. I.; Gill, P. M.; Head-Gordon, M. Advances in molecular quantum chemistry contained in the Q-Chem 4 program package. Molecular Physics 2015, 113, 184-215.

(15) Zhou, Y.; Wang, S.; Li, Y.; Zhang, Y. Methods in enzymology; Elsevier, 2016; Vol. 577; pp 105-118.

(16) Zhang, Y. Pseudobond ab initio QM/MM approach and its applications to enzyme reactions. Theoretical Chemistry Accounts 2006, 116, 43-50.

(17) Roux, B. The calculation of the potential of mean force using computer simulations. Computer physics communications 1995, 91, 275-282.

(18) Grossfield, A. WHAM: an implementation of the weighted histogram analysis method.

(19) Seritan, S.; Bannwarth, C.; Fales, B. S.; Hohenstein, E. G.; Kokkila-Schumacher, S. I. L.; Luehr, N.; Snyder, J. W.; Song, C.; Titov, A. V.; Ufimtsev, I. S.; Martínez, T. J. 
TeraChem: Accelerating electronic structure and ab initio molecular dynamics with graphical processing units. The Journal of Chemical Physics 2020, 152, 224110.

(20) Seritan, S.; Bannwarth, C.; Fales, B. S.; Hohenstein, E. G.; Isborn, C. M.; KokkilaSchumacher, S. I. L.; Li, X.; Liu, F.; Luehr, N.; Snyder Jr., J. W.; Song, C.; Titov, A. V.; Ufimtsev, I. S.; Wang, L.-P.; Martínez, T. J. TeraChem: A graphical processing unitaccelerated electronic structure package for large-scale ab initio molecular dynamics. WIREs Computational Molecular Science n/a, e1494.

(21) Salomon, O.; Reiher, M.; Hess, B. A. Assertion and validation of the performance of the B3LYP* functional for the first transition metal row and the G2 test set. The Journal of Chemical Physics 2002, 117, 4729-4737.

(22) Siig, O. S.; Kepp, K. P. Iron(II) and Iron(III) Spin Crossover: Toward an Optimal Density Functional. The Journal of Physical Chemistry A 2018, 122, 4208-4217.

(23) Szilagyi, R. K.; Winslow, M. A. On the accuracy of density functional theory for iron-sulfur clusters. Journal of Computational Chemistry 2006, 27, 1385-1397.

(24) Jang, H.; Qiu, Y.; Hutchings, M. E.; Nguyen, M.; Berben, L. A.; Wang, L.-P. Quantum chemical studies of redox properties and conformational changes of a four-center iron CO2 reduction electrocatalyst. Chem. Sci. 2018, 9, 2645-2654.

(25) Weigend, F.; Ahlrichs, R. Balanced basis sets of split valence, triple zeta valence and quadruple zeta valence quality for $\mathrm{H}$ to Rn: Design and assessment of accuracy. Phys. Chem. Chem. Phys. 2005, 7, 3297-3305.

(26) Zheng, J.; Xu, X.; Truhlar, D. G. Minimally augmented Karlsruhe basis sets. Theoretical Chemistry Accounts 2011, 128, 295-305.

(27) Roy, L. E.; Hay, P. J.; Martin, R. L. Revised Basis Sets for the LANL Effective Core Potentials. Journal of Chemical Theory and Computation 2008, 4, 1029-1031. 
(28) Grimme, S.; Ehrlich, S.; Goerigk, L. Effect of the damping function in dispersion corrected density functional theory. Journal of Computational Chemistry 2011, 32, 14561465.

(29) Cossi, M.; Rega, N.; Scalmani, G.; Barone, V. Energies, structures, and electronic properties of molecules in solution with the C-PCM solvation model. Journal of Computational Chemistry 2003, 24, 669-681.

(30) Lange, A. W.; Herbert, J. M. A smooth, nonsingular, and faithful discretization scheme for polarizable continuum models: The switching/Gaussian approach. The Journal of Chemical Physics 2010, 133, 244111.

(31) Liu, F.; Luehr, N.; Kulik, H. J.; Martínez, T. J. Quantum Chemistry for Solvated Molecules on Graphical Processing Units Using Polarizable Continuum Models. Journal of Chemical Theory and Computation 2015, 11, 3131-3144.

(32) Wang, L.-P.; Song, C. Geometry optimization made simple with translation and rotation coordinates. The Journal of Chemical Physics 2016, 144, 214108.

(33) Malick, D. K.; Petersson, G. A.; Montgomery, J. A. Transition states for chemical reactions I. Geometry and classical barrier height. The Journal of Chemical Physics 1998, 108, 5704-5713.

(34) Mammen, M.; Shakhnovich, E. I.; Deutch, J. M.; Whitesides, G. M. Estimating the Entropic Cost of Self-Assembly of Multiparticle Hydrogen-Bonded Aggregates Based on the Cyanuric Acid·Melamine Lattice. The Journal of Organic Chemistry 1998, 63, 3821-3830.

(35) Plata, R. E.; Singleton, D. A. A Case Study of the Mechanism of Alcohol-Mediated Morita Baylis-Hillman Reactions. The Importance of Experimental Observations. Journal of the American Chemical Society 2015, 137, 3811-3826. 
(36) Tuguldurova, V. P.; Fateev, A. V.; Poleshchuk, O. K.; Vodyankina, O. V. Theoretical analysis of glyoxal condensation with ammonia in aqueous solution. Phys. Chem. Chem. Phys. 2019, 21, 9326-9334.

(37) Tissandier, M. D.; Cowen, K. A.; Feng, W. Y.; Gundlach, E.; Cohen, M. H.; Earhart, A. D.; Coe, J. V.; Tuttle, T. R. The Proton's Absolute Aqueous Enthalpy and Gibbs Free Energy of Solvation from Cluster-Ion Solvation Data. The Journal of Physical Chemistry A 1998, 102, 7787-7794.

(38) Wang, L.-P.; Wu, Q.; Van Voorhis, T. Acid-Base Mechanism for Ruthenium Water Oxidation Catalysts. Inorganic Chemistry 2010, 49, 4543-4553.

(39) Reiss, H.; Heller, A. The absolute potential of the standard hydrogen electrode: a new estimate. The Journal of Physical Chemistry 1985, 89, 4207-4213.

(40) Exner, K. S.; Sohrabnejad-Eskan, I.; Over, H. A Universal Approach To Determine the Free Energy Diagram of an Electrocatalytic Reaction. ACS Catalysis 2018, 8, 1864-1879, Publisher: American Chemical Society.

(41) Neese, F.; Wennmohs, F.; Becker, U.; Riplinger, C. The ORCA quantum chemistry program package. The Journal of Chemical Physics 2020, 152, 224108.

(42) van Wullen, C. Molecular density functional calculations in the regular relativistic approximation: Method, application to coinage metal diatomics, hydrides, fluorides and chlorides, and comparison with first-order relativistic calculations. The Journal of Chemical Physics 1998, 109, 392-399.

(43) Barone, V.; Bencini, A.; Fantucci, P. Recent Advances in Density Functional Methods; WORLD SCIENTIFIC, 2002.

(44) Weigend, F.; Ahlrichs, R. Balanced basis sets of split valence, triple zeta valence and 
quadruple zeta valence quality for $\mathrm{H}$ to Rn: Design and assessment of accuracy. Phys. Chem. Chem. Phys. 2005, 7, 3297-3305.

(45) Izsak, R.; Neese, F. An overlap fitted chain of spheres exchange method. The Journal of Chemical Physics 2011, 135, 144105.

(46) Neese, F. Prediction of electron paramagnetic resonance g values using coupled perturbed Hartree-Fock and Kohn-Sham theory. The Journal of Chemical Physics 2001, $115,11080-11096$.

(47) Neese, F. Metal and ligand hyperfine couplings in transition metal complexes: The effect of spin-orbit coupling as studied by coupled perturbed Kohn-Sham theory. The Journal of Chemical Physics 2003, 118, 3939-3948. 